\title{
Leo Kenis, Ernestine Van der Wall (eds.), Religious Modernism in the Low Countries
}

Leuven-Paris-Walpole (MA), Peeters, coll. « Bibliotheca Ephemeridum Theologicarum Lovaniensium », CCIV 2013, VIII-271 p., illustrations

\section{Willem Frijhoff}

\section{(2) OpenEdition}

\section{Journals}

Édition électronique

URL : http://journals.openedition.org/assr/28257

DOI : $10.4000 /$ assr.28257

ISSN : $1777-5825$

Éditeur

Éditions de l'EHESS

Édition imprimée

Date de publication : 31 décembre 2016

Pagination : 331

ISSN : 0335-5985

\section{Référence électronique}

Willem Frijhoff, «Leo Kenis, Ernestine Van der Wall (eds.), Religious Modernism in the Low Countries », Archives de sciences sociales des religions [En ligne], 176 | octobre-décembre 2016, mis en ligne le 18 juillet 2017, consulté le 24 septembre 2020. URL : http://journals.openedition.org/assr/28257 ; DOI : https://doi.org/10.4000/assr.28257

Ce document a été généré automatiquement le 24 septembre 2020.

(c) Archives de sciences sociales des religions 


\section{Leo Kenis, Ernestine Van der Wall (eds.), Religious Modernism in the Low Countries}

Leuven-Paris-Walpole (MA), Peeters, coll. « Bibliotheca Ephemeridum Theologicarum Lovaniensium », CCIV 2013, VIII-271 p., illustrations

\section{Willem Frijhoff}

\section{RÉFÉRENCE}

Leo Kenis, Ernestine Van der Wall (eds.), Religious Modernism in the Low Countries, Leuven-Paris-Walpole (MA), Peeters, coll. « Bibliotheca Ephemeridum Theologicarum Lovaniensium », CCIV 2013, VIII-271 p., illustrations

1 Issu de deux conférences tenues en 2003 et 2008, ce volume centré sur les différentes manifestations $\mathrm{du}$ modernisme entend rompre l'opposition religieuse traditionnellement construite entre les deux parties des anciens Pays-Bas, un Nord supposé protestant (les Pays-Bas actuels) et un Sud catholique (la Belgique). La thèse centrale est celle d'une histoire partagée (shared history) avec des accents différents selon les pays. Les auteurs entendent dépasser les approches confessionnelles en comparant et confrontant les mouvements modernistes catholiques et protestants, tout en nuançant les concepts, «modernisme» n'étant pas forcément identique au mouvement progressiste dans les Églises. Les quatorze contributions sont encadrées par une introduction qui met le thème en chantier, et un beau chapitre final par Ernestine van der Wall sur la perception que les modernistes catholiques et protestants développaient d'eux-mêmes, comme héros souvent tragiques de la guerre entre science et religion et comme purificateurs et rénovateurs d'un christianisme devenu obsolète.

2 Sous le titre "The Matrix of Modernism ", C. J. T. Talar résume d'abord l'évolution intellectuelle $\mathrm{du}$ modernisme français, d'Alfred Loisy (qui donna son nom au « loysisme » avant que le terme modernisme ne fût monnayé) et George Tyrrell à des 
exégètes comme le père dominicain Marie-Joseph Lagrange. En accord avec les analyses d'Émile Poulat, il accentue le passage d'une science catholique ou chrétienne à cette authentique science religieuse qui a enfanté le modernisme "naturaliste ", devenu la bête noire des exégètes conservateurs, puis des autorités catholiques dans le syllabus Lamentabili sane exitu et l'encyclique Pascendi dominici gregis de 1907 de Pie X, dont Claus Arnold décrit ici la genèse. Ward De Pril compare la réception de la Vie de Jésus d'Ernest Renan en Belgique où, pareil à ce qui se passait en France, elle fut tout de suite réfutée par le bibliste de Louvain Thomas Lamy, à son accueil aux Pays-Bas, où la réception était plus nuancée. Dans les milieux protestants libéraux des Pays-Bas, la critique biblique, proche des Allemands, était déjà bien développée, et le positivisme, en différentes nuances, y était assez courant dans l'approche de l'histoire religieuse (Kaat Wils). La Vie de Jésus parut d'ailleurs en traduction néerlandaise dès sa publication en 1863 (rappelons que, par son mariage avec la nièce du peintre hollandais Ary Scheffer, Renan avait des liens suivis avec les Pays-Bas). Cependant, l'auteur montre bien que, contrairement aux théologiens protestants libéraux (Leyde), leurs collègues orthodoxes (Utrecht) aussi bien que les théologiens catholiques réfutaient d'emblée la Vie de Jésus, même si tel théologien réformé orthodoxe maintenait contre les catholiques le droit au libre examen. Dès 1871, dans une analyse serrée de la genèse de la théologie moderne, Abraham Kuyper, un esprit néo-calviniste rigoureux et le futur fondateur de l'université libre d'Amsterdam, diagnostiquait le modernisme comme "une fata morgana dans le domaine chrétien" - jugement qui ferait date dans l'orthodoxie protestante (Arie Molendijk). Kuyper rejeta le modernisme non seulement pour des raisons tenant à sa théologie, mais aussi dans un sens plus global : comme il l'a argué en 1898 dans ses fameuses Stone Lectures à Princeton, le modernisme entendait construire un monde naturel sans héritage chrétien. Les Kuypériens et leurs alliés américains, les presbytériens conservateurs, qui croyaient en une Bible sans erreur possible, en venaient rapidement aux prises avec la critique biblique très influente du théologien réformé Abraham Kuenen, qui proposait une vision « reconstructionniste » de la genèse de la Pentateuque et restait réticent à l'égard des récits de miracles. Si les conservateurs néo-calvinistes maintenaient leur attitude rigoriste face à ces tendances proches du modernisme, il n'en résultait pas moins auprès de certains, tel Arie Noordtzij, l'idée d'une "critique historique " légitime, même si ce terme n'avait que peu en commun avec le sens que les modernistes de la ligne dure y donnaient (Niels van Driel). Dans l'entre-deux-guerres, le malaise croissant à propos de l'enfermement de la théologie reformée dans les positions kuypériennes conduisait aussi bien à un certain dynamisme réformateur qu'à une exacerbation des positions néo-calvinistes auprès de théologiens tels que Klaas Schilder, leader d'une des nombreuses sécessions de la tradition réformée (George Harinck). À l'autre extrémité de la palette des courants théologiques protestants, les remontrants (une sécession libérale de l'Église réformée néerlandaise à la suite du Synode de Dordrecht tenu en 1619) embrassaient assez rapidement le courant moderniste, renforcé dès 1872 après le transfert de leur séminaire d'Amsterdam à la faculté de Leyde (Eric Cossee). Le paysage protestant émietté des Pays-Bas favorisait en fait une multitude d'interprétations de type moderniste, pouvant aller jusqu'au « christianisme athée » d'Anton van Hamel refusant toute théologie métaphysique (Hans Trapman).

3 Luc Courtois montre que la crise moderniste n'a pas épargné la Belgique, comme cela est souvent pensé par ceux qui privilégient dans cette histoire la condamnation d'Alfred Loisy et de ses partisans, mais que le modernisme y prenait plutôt la forme 
d'une théologie biblique progressiste dans le sillage de Lagrange, comme Lieve Gevers l'avait déjà suggéré. Dans son panorama du modernisme belge, Courtois relève en particulier les carrières d'Hippolyte Delahaye et Paulin Ladeuze et les actions secrètes et subtiles pour la défense des théologiens progressistes de la part du Cardinal Désiré Mercier, archevêque de Malines par ailleurs aussi autoritaire que conservateur, dont James Kelly décrit ici les rapports complexes avec George Tyrrell. Certains catholiques belges exploraient ouvertement les limites de ce qui était acceptable pour les instances romaines, tel Jacques Laminne enseignant la théorie de l'évolution à Louvain (Raf De Bont).

4 On a dit que le jansénisme était surtout le produit de définitions formulées par les antijansénistes. La même remarque vaudrait probablement pour le modernisme dont l'unité assez factice repose avant tout sur la perception de ses détracteurs. Si les modernistes catholiques et protestants des Pays-Bas et de la Belgique puisaient bien dans des sources semblables, pouvaient avoir les mêmes objectifs scientifiques et furent l'objet de campagnes de détractation et persécution similaires, le monde catholique centralisé et hyper-hiérarchisé de cette époque, dans lequel le catholicisme minoritaire des Pays-Bas jouait la carte de l'obéissance inconditionnelle au Vatican, est extrêmement difficile à comparer avec la fragmentation des Églises protestantes et plus encore de leur univers théologique. Celui-ci allait dans les Pays-Bas jusqu'à un franc émiettement qui a toujours fasciné les observateurs, y compris les réformés euxmêmes. Cette fascination pour les micro-évolutions du protestantisme néerlandais, où chaque théologien crée son propre courant d'idées et parfois sa propre communauté confessionnelle, se retrouve dans ce volume. Prolixe à l'égard des néo-calvinistes auxquels le terme de "modernisme » au sens fort ne parait applicable que par analogie, il ne décrit le monde catholique néerlandais qu'en quelques traits sommaires qui ne lui font pas vraiment justice. Aussi la confrontation des évolutions dans les deux confessions majeures reste-t-elle un peu à l'arrière-plan, tout comme la comparaison entre les deux pays, effectivement très différents en ce domaine. Le lecteur trouve dans ce recueil bien des éléments, mais il doit établir la comparaison lui-même. Par ailleurs, l'histoire partagée dont parle l'introduction revient ici tout au plus à un parallélisme historique. Rares paraissent avoir été les vraies rencontres interconfessionnelles dans ce domaine. Pour construire un vrai modèle de partage, il aurait peut-être fallu moins de théologiens ou d'historiens de l'Église parmi les auteurs, et plus d'historiens de la culture ou de sociologues intéressés par d'autres paramètres. Un seul article s'en approche vraiment, celui de Herman Noordegraaf. Partant de l'étude maîtresse du sociologue J.P. Kruijt, parue en 1933, sur les origines de la désertion des Églises (onkerkelijkheid ou en anglais secularism) aux Pays-Bas, il réfléchit sur la question de savoir si le modernisme a pu favoriser l'incroyance et la sécularisation et introduit bien d'autres facteurs que la critique biblique ou le mouvement des idées religieuses. 